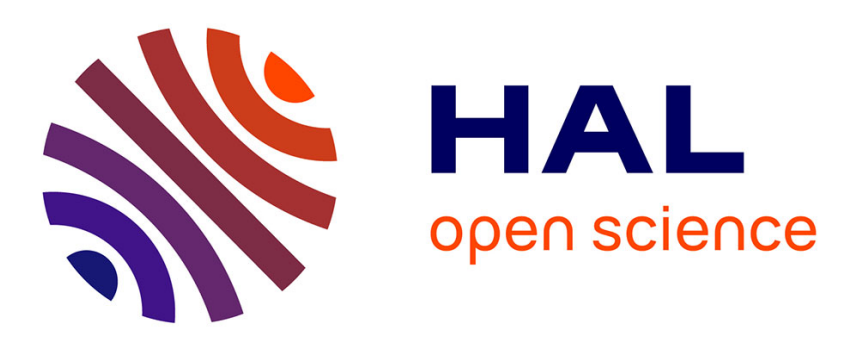

\title{
A new simple device to estimate thermophysical properties of insulating materials
}

Bruno Ladevie, Olivier Fudym, J.C. Batsale

\section{To cite this version:}

Bruno Ladevie, Olivier Fudym, J.C. Batsale. A new simple device to estimate thermophysical properties of insulating materials. International Communications in Heat and Mass Transfer, 2000, 27 (4), pp.473 - 484. 10.1016/S0735-1933(00)00130-5 . hal-01651376

\section{HAL Id: hal-01651376 https://imt-mines-albi.hal.science/hal-01651376}

Submitted on 7 Nov 2019

HAL is a multi-disciplinary open access archive for the deposit and dissemination of scientific research documents, whether they are published or not. The documents may come from teaching and research institutions in France or abroad, or from public or private research centers.
L'archive ouverte pluridisciplinaire HAL, est destinée au dépôt et à la diffusion de documents scientifiques de niveau recherche, publiés ou non, émanant des établissements d'enseignement et de recherche français ou étrangers, des laboratoires publics ou privés. 


\title{
A NEW SIMPLE DEVICE TO ESTIMATE THERMOPHYSICAL PROPERTIES OF INSULATING MATERIALS
}

\author{
B. Ladevie, O. Fudym \\ Ecole des Mines d'Albi Carmaux, Centre Energétique et Environnement, \\ Campus Jarlard, 81013 ALBI CT Cedex 09; \\ Tel: 05.63.49.31.12; Email: ladevie@enstimac.fr \\ J.C. Batsale \\ LEPT-ENSAM (URA CNRS 873) \\ Esplanade des Arts et Métiers, 33405 TALENCE Cedex; \\ Tel: 05.56.84.54.25; Email: batsale@lept-ensam.u-bordeaux.fr
}

(Communicated by M. Lebouché)

\begin{abstract}
The method described here is to measure thermal conductivity of super insulating materials. The principle is based on a simple transient experiment and a single temperature measurement. The main idea is to control the heat flux diffusion in the sample by the adjunction of a semi infinite highly conductive medium.

An analytical 3D model for transient heat transfer was developed. The resolution of the inverse problem enables the thermophysical properties of insulating materials to be identified.
\end{abstract}

\section{Introduction}

Designing an experimental device to estimate thermophysical conductive properties of superinsulating materials is generally difficult.

1D permanent transfer in the case of a guarded hot box apparatus (see Mumaw, 1973) requires many precautions (regulated heat sink, fluxmeters, regulated guard ring etc.).

The use of the transient flash method (see Parker et al , 1961; Degiovanni, 1977) to measure thermal diffusivity is also difficult due to the influence of heat losses around the sample. Some authors (see Martin et al, 1994) have tried to improve the experiment by adding 2 metal plates on either side of the sample. However, the experiment becomes more complicated and the influence of the lateral heat losses is only attenuated. 
Lastly, the popular hot wire method (see Carslaw and Jaeger, 1959) remains easier to implement. However, even if the cylindrical semi infinite medium assumption avoids the problem of considering heat losses and the ends of the medium, some loss effects are possible at the ends of the wire. Moreover, large temperature gradients around the wire, due to the geometry, can introduce some estimation errors in the case of non linear transfer.

The new device proposed here tries to combine all the advantages of the previous methods. The main idea is to control the heat flux diffusion inside the insulating sample by addition of a highly conductive metal support. No regulated heat sink and flux meter is then needed. A probe similar to the hot wire system is used to measure only one temperature evolution on a planar heating device. Therefore, the transfer becomes quite 1D and steady, even if a model considering 3D geometry and transient state is necessary.

This device is then a simple complementary approach of hot wire method in order to comfirm this kind of measurement.

The principle of the experiment is first explained and a 3D model is proposed. Asymptotic expansions give the first step of a 3 parameters estimation method.

Experimental validation is shown with convenient appropriate size recommendations.

\section{Modelling}

The device described in figure 1 can be modelised using the following system:

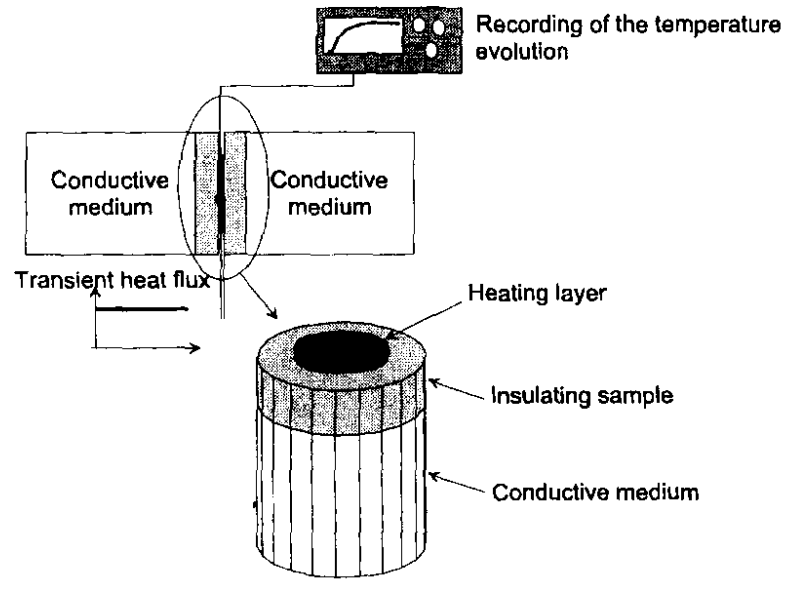

(a)

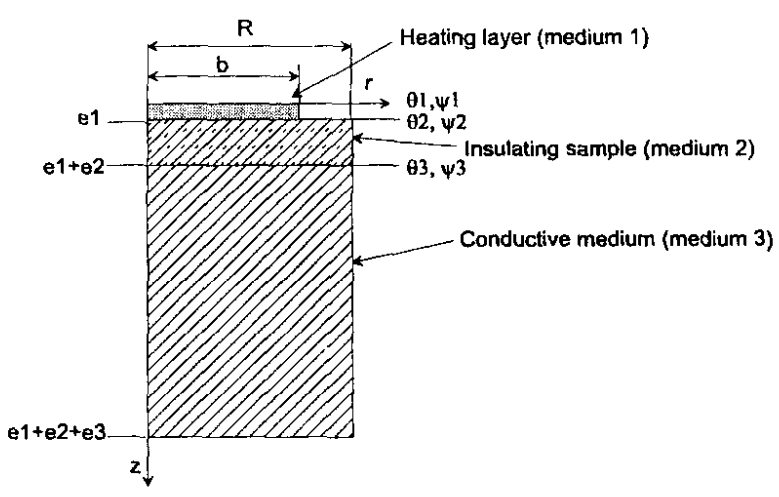

(b)

FIG 1

Scheme of the device and Main geometrical parameters of the device 
Transfer inside the heating layer (medium 1):

This layer is metallic and considered to be infinitely thin. Thus temperature distribution is assumed to be uniform versus $\mathrm{z}$-direction. It yelds then:

$$
\left(\rho c_{p}\right)_{l} e_{1} \frac{\partial T_{1}^{*}}{\partial t}=Q+\Phi_{2}\left(z=e_{l}\right)
$$

Where Q is the Joule effect heat flux and $\Phi_{2}\left(z=e_{1}\right)$ describes the heat flux penetrating inside the insulating sample (medium 2).

Transfer inside the insulating sample (medium 2) and inside the conductive medium (medium 3):

Heat transfert is here assumed to be purely conductive and the sample isotropic. It yields then in cylindrical coordinates:

$$
\left(\frac{\partial^{2} T_{i}^{*}}{\partial r^{2}}+\frac{1}{r} \frac{\partial^{2} T_{i}^{*}}{\partial r^{2}}\right)+\frac{\partial^{2} T_{i}^{*}}{\partial z^{2}}=\frac{I}{a_{t}} \frac{\partial T_{i}^{*}}{\partial t} i=2,3
$$

with flux and temperature continuity at interfaces between media 1 and 2 , and media 2 and 3 .

Flux is assumed to be null at $r=R$.

Initially, the whole system is assumed to be at uniform temperature To. A new variable is then considered such as $T_{i}=T_{i}^{*}-T o$.

To write the previous system in a less complex form, Laplace and Hankel transforms yiels :

$$
\theta_{i}\left(\alpha_{n}, z, p\right)=\int_{0}^{R} \int_{0}^{\infty} T(r, z, t) e^{-p t} J_{0}\left(\alpha_{n} r\right) r d t d r
$$

Then equation (2) becomes an ordinary differential equation:

$$
\frac{d^{2} \theta_{1}}{d z^{2}}=\left(\frac{p}{a_{i}}+\alpha_{n}^{2}\right) \theta_{i}
$$

with $\alpha_{n}$ : roots of a transcendental equation such as: $J_{l}\left(\alpha_{n} R\right)=0$. We use the mumerical approximation of $\alpha_{n}$ :

$$
\alpha_{0}=0 \text { and } \alpha_{n} R=n \pi+\frac{\pi}{4}-\frac{3}{\left(8 n \pi+\frac{\pi}{4}\right)}
$$

with heat flux definition such as:

$$
\Psi_{i}\left(\alpha_{n}, p, z\right)=-\lambda_{i} \frac{d \theta_{i}\left(\alpha_{n}, p, z\right)}{d z}
$$


Expressions (4) and (5) are then equivallent to a quadripole presentation (see Batsale et al, 1994) such as :

$$
\frac{d}{d z}\left[\begin{array}{l}
\theta_{t}\left(\alpha_{n}, p, z\right) \\
\psi_{1}\left(\alpha_{n}, p, z\right)
\end{array}\right]=\left[\begin{array}{lr}
0 & -1 / \lambda_{t} \\
-\left(\rho c_{p}\right)_{i} p+\alpha_{n}^{2} & 0
\end{array}\right]\left[\begin{array}{l}
\theta_{1}\left(\alpha_{n}, p, z\right) \\
\psi_{i}\left(\alpha_{n}, p, z\right)
\end{array}\right]
$$

The solution of (6) gives a simple relationship between temperature and flux vector at the limits of each medium such as:

$$
\left[\begin{array}{l}
\theta_{i}\left(\alpha_{n}, p, \sum_{j=l}^{i-1} e_{j}\right) \\
\psi_{i}\left(\alpha_{n}, p, \sum_{j=I}^{i-l} e_{j}\right)
\end{array}\right]=\left[\begin{array}{ll}
\mathrm{A}_{\mathrm{i}} & \mathrm{B}_{1} \\
\mathrm{C}_{1} & \mathrm{D}_{1}
\end{array}\right]\left[\begin{array}{l}
\theta_{i}\left(\alpha_{n}, p, \sum_{j=1}^{l} e_{j}\right) \\
\psi_{i}\left(\alpha_{n}, p, \sum_{j=1}^{i} e_{j}\right)
\end{array}\right]
$$

with

$$
\begin{aligned}
& A_{1}=D_{i}=\cosh \left(K_{1} e_{i}\right) \quad B_{1}=\frac{\sinh \left(K_{t} e_{i}\right)}{\lambda_{i} K_{i}} \\
& C_{i}=\lambda_{i} K_{t} \sinh \left(K_{i} e_{i}\right) \quad \text { and } K_{i}=\sqrt{\frac{p}{a_{t}}+\alpha_{n}^{2}}
\end{aligned}
$$

Medium 3 is considered as semi-infinite so that the transformed temperature distribution is under the form:

$$
\theta_{3}\left(\alpha_{n}, p, z\right)=\theta_{3}\left(\alpha_{n}, p, e_{1}+e_{2}\right) \exp \left(-K_{3}\right) z
$$

Then it yields the following:

$$
\begin{gathered}
\theta_{3}\left(\alpha_{n}, p, z\right)=\frac{1}{\lambda_{3} K_{3}} \exp \left(-K_{3} z\right) \\
\text { and }\left.\psi_{3}\left(\alpha_{n}, p, z\right)\right|_{z=e_{1}+e_{2}}=-\left.\lambda_{3} \frac{d \theta_{3}\left(\alpha_{n}, p, z\right)}{d z}\right|_{z=e_{1}+e_{2}}=\lambda_{3} K_{3} \theta_{3}\left(\alpha_{n}, p, e_{1}+e_{2}\right)
\end{gathered}
$$

The entire system can be described in transformed space as:

$$
\left[\begin{array}{l}
\theta_{1}\left(\alpha_{n}, p, 0\right) \\
\Psi_{1}\left(\alpha_{n}, p, 0\right)
\end{array}\right]=\left[\begin{array}{ll}
1 & 0 \\
\left(\rho c_{p}\right), e_{1} p & 1
\end{array}\right]\left[\begin{array}{ll}
A_{2} & \mathrm{~B}_{2} \\
C_{2} & \mathrm{D}_{2}
\end{array}\right]\left[\begin{array}{l}
\theta_{3}\left(\alpha_{n}, p, e_{1}+e_{2}\right) \\
\Psi_{3}=\lambda_{3} K_{3} \theta_{3}\left(\alpha_{n}, p, e_{1}+e_{2}\right)
\end{array}\right]
$$

The transformed temperature measured on the heating plate is then:

$$
\theta_{1}\left(\alpha_{n}, p, 0\right)=\frac{\left\{A_{2}+B_{2} \lambda_{3} K_{3}\right\} \psi_{1}\left(\alpha_{n}, p, 0\right)}{C_{2}+A_{2}\left(\rho c_{p}\right)_{l} e_{1} p+\lambda_{3} K_{3}\left\{B_{2}\left(\rho c_{p}\right)_{1} e_{l} p+D_{2}\right\}}
$$


Such an expression is rather complex and can be inverted in real space by numerical computation. Nevertheless, some asymptotic expansions can give some insights to the physical behaviour of the system.

\section{Physical Behaviour of the System Through Asymptotic Assumptions of the Model}

Asymptotic behaviour of $(11)$ when $\left(\left(\rho c_{p}\right)_{1} e_{1}=0_{2} t \rightarrow \infty\right.$ and $\underline{\left.\lambda_{3} \rightarrow \infty\right)}$

Expression (11) yields then:

$$
\theta_{1}\left(\alpha_{n}, p, 0\right)=\frac{\operatorname{th}\left(\alpha_{n} e_{2}\right)}{\lambda_{2} \alpha_{n}} \frac{Q b J_{1}\left(\alpha_{n} b\right)}{p \alpha_{n}}
$$

In real space a relationship between the temperature measured at the center of the plate $(r=0)$ gives:

$$
T(0,0, t)=\frac{e_{2} Q b^{2}}{\lambda_{2} R^{2}}+\frac{2 Q b^{2}}{\lambda_{2} R^{2}} \sum_{n=1}^{\infty} \frac{t h\left(\alpha_{n} e_{2}\right)}{b \alpha_{n}^{2}} \frac{J_{1}\left(\alpha_{n} b\right)}{J_{0}^{2}\left(\alpha_{n} R\right)}=R_{c} Q
$$

- Where $R c$ is the constriction resistance between the heating plate and the semi-infinite cool plate. The definition of $R c$ is then :

$$
R c=\left(\frac{e_{2}}{\lambda_{2}}+\frac{2}{\lambda_{2}} \sum_{n=1}^{\infty} \frac{t h\left(\alpha_{n} e_{2}\right)}{b \alpha_{n}^{2}} \frac{J_{1}\left(\alpha_{n} b\right)}{J_{0}^{2}\left(\alpha_{n} R\right)}\right) \frac{b^{2}}{R^{2}}
$$

$-\lambda_{3} \rightarrow \infty$ is assumed to be equivalent to Dirichlet zero temperature condition at $z=e 1+e 2+e 3$ depth.

Asymptotic behaviour of $(11)$ when $\left(\left(\rho c_{p}\right)_{1} e_{1}=0 \underline{\text { and }}\left(\rho c_{p}\right)_{2} e_{2}=0\right)$

$$
\theta_{1}\left(\alpha_{n}, p, 0\right)=\frac{1}{\sqrt{\lambda_{3}\left(\rho c_{p}\right)_{3}} \sqrt{p}} \frac{Q b J_{1}\left(\alpha_{n} b\right)}{p \alpha_{n}}+\frac{\operatorname{th}\left(\alpha_{n} e_{2}\right)}{\lambda_{2} \alpha_{n}} \frac{Q b J_{1}\left(\alpha_{n} b\right)}{p \alpha_{n}}
$$

In real space, a relationship between the temperature measured at the center of the plate $(r=0)$ gives:

$$
T(0,0, t)=\frac{Q b^{2}}{R^{2} \sqrt{\pi} \sqrt{\lambda_{3}\left(\rho c_{p}\right)_{3}}} \sqrt{t}+R c Q
$$


Such an approximated expression as (16) is more convenient to understand the physical evolution of temperature $T(r=0, z=0, t)$ (see an example of comparison between expression (11) and (16) on figure 2).

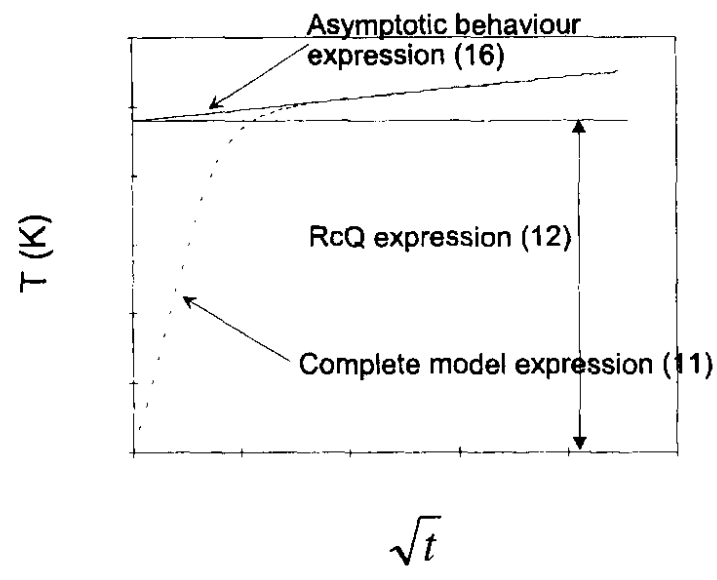

FIG 2

Example of comparison between expressions (11) and (16).

The first term depends only on the properties of medium 3. The second term (constant) depends only on thermal conductivity $\lambda_{2}$ and geometrical parameters

A first estimation method can be deduced:

* estimation of $\frac{Q}{\sqrt{\lambda_{3}\left(\rho c_{p}\right)_{3}}}$ with the slope versus $\sqrt{t}$ (see figure 2).

* estimation of $R c Q$ with the origin ordinate (extrapolated).

* the value of $\left(\rho c_{p}\right)_{2}$ is fixed at $\left(\rho c_{p}\right)_{1}$ to begin the numerical estimation.

Since the Joule effect energy is estimated by electrical measurement on the heating resistance, estimation of effusivity $\sqrt{\lambda_{3}\left(\rho c_{p}\right)_{3}}$ of medium 3 is a good way to verify the conservation of the heat flow inside the system.

This non dependance between thermophysical properties of media 2 and 3 can constitute the basic step to implement a classical numerical estimation method which minimize the norm between experimental values and exact expression (11). We have used a Nelder Mead minimization algorithm ( see Press et al, 1986). 


\section{Experiment and Results}

\section{Description of the device:}

The scheme of the device is given on figure 1-a.

The heating probe is made with two thin foil resistances (MINCO type [15]) in which a K-type thermocouple is inserted to measure the temperature evolution of the probe. An electric generator supplies an step power exitation to the probe. The thermocouple signal is recorded on a digital oscilloscope.

The only precaution with the samples is to respect the size, parallelism and symmetry.

A $10 \mathrm{~cm}$ thick brass cylinder is used as a conductive semi infinite medium.

The validation of the device has been made using other classical methods (such as hot wire, hot plane,...).

Experimental temperature evolution is given on figure (3) and nominal values are given in table 1.

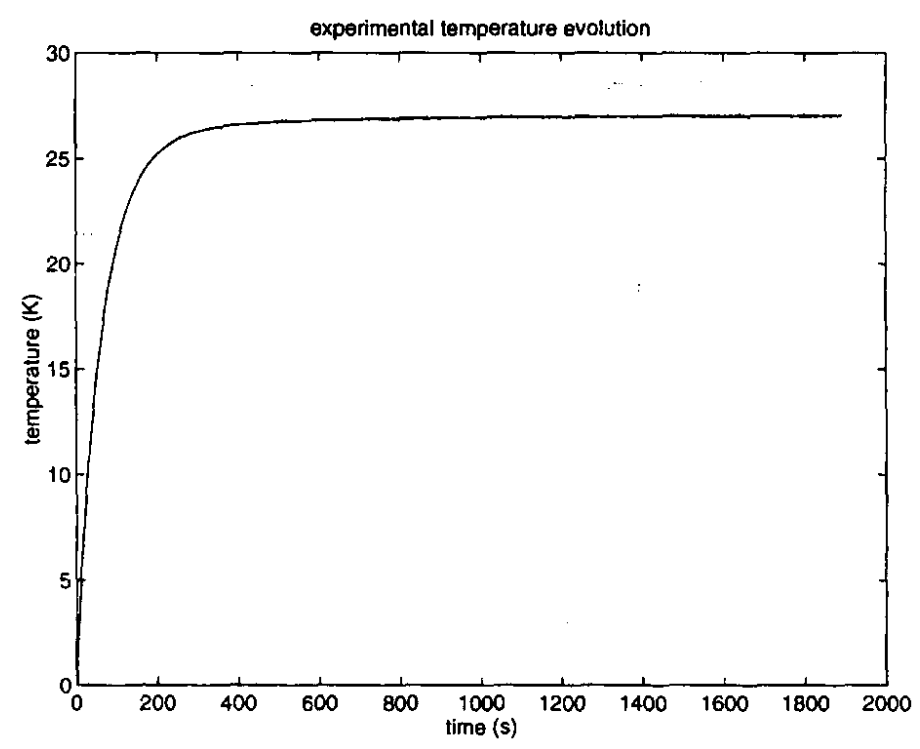

FIG 3

Experimental temperature evolution.

TABLE 1

Nominal values:

Excitation heat flux

$\mathrm{Q}=444.48 \mathrm{Wm}^{-2}$

Thermal conductivity of medium 3

$\lambda_{3}=150 \mathrm{~W} \cdot \mathrm{m}^{-1} \cdot \mathrm{K}^{-1}$ 


\begin{tabular}{ll}
\hline Volumetric thermal capacity of medium 3 & $\left(\rho \mathrm{c}_{\mathrm{p}}\right)_{3}=3.610^{6} \mathrm{~J} \cdot \mathrm{m}^{-3} \cdot \mathrm{K}^{-1}$ \\
Volumetric thermal capacity of medium 3 & $\left(\rho \mathrm{c}_{\mathrm{p}}\right)_{1}=3.2610^{6} \mathrm{~J} \cdot \mathrm{m}^{-3} \cdot \mathrm{K}^{-1}$ \\
Lateral dimensions 1 & $\mathrm{b}=4.510^{-3} \mathrm{~m}$ \\
Lateral dimensions of medium 2 and 3 & $\mathrm{R}=510^{-2} \mathrm{~m}$ \\
Thickness of medium 1 & $\mathrm{e}_{1}=2.10^{-4} \mathrm{~m}$ \\
Thickness of medium 2 & $\mathrm{e}_{2}=5.4 .10^{-3} \mathrm{~m}$ \\
\hline
\end{tabular}

The material used is a sample of furnace thermal insulation: Isosilikat (table 2).

TABLE 2

Results

\begin{tabular}{|c|c|c|c|}
\hline & Hot Wire method & Constructor data & Our method \\
\hline$\lambda(W / m K)$ & 0.086 & 0.088 & $\mathbf{0 . 0 8 7}$ \\
$\left(\rho c_{p}\right)_{2}\left(J \cdot m^{-3} \cdot K^{-1}\right)$ & & $2.3310^{5}$ & $\mathbf{2 . 6 9 1 0 ^ { 5 }}$ \\
$E_{3}\left(J \cdot m^{-2} \cdot K^{\prime} s^{-1 / 2}\right)$ & & $2.3210^{4}$ & $\mathbf{2 . 2 3 ~ 1 0 ^ { 4 }}$ \\
\hline
\end{tabular}

We have observed that the rough estimation from the expression is very accurate.

Calculation of the constriction resistance $R c(14)$, gives an excellent first estimation of the thermal conductivity $\lambda_{2}$. In the proposed case, we obtain $\lambda_{2}=0.087 \mathrm{~W} / \mathrm{mK}$. We begin the numerical estimation with this first value.

Study of measurement noise influence:

This problem can be studied with the linear least square approach (Beck et Arnold, 1977). The measurement temperature $\hat{T}(t)$ is linked to real temperature $T(t)$ by the following expression :

$$
\hat{T}(t)=T(t)+e_{T}(t)
$$

Where $e_{T}(t)$ is a random variable called " measurement error ». The mean value is assumed to be zero and stantard deviation to be constant for each $t$ considered, such as (from expression (16)).

$$
\left[\begin{array}{l}
\hat{T}_{1} \\
\cdot \\
\cdot \\
\hat{T}_{n}
\end{array}\right]=\left[\begin{array}{ll}
\sqrt{t_{1}} & 1 \\
\cdot & \cdot \\
\cdot & \cdot \\
\sqrt{t_{n}} & 1
\end{array}\right]\left[\begin{array}{l}
\beta_{1} \\
\beta_{2}
\end{array}\right]=\left[X\left[\begin{array}{l}
\beta_{1} \\
\beta_{2}
\end{array}\right]\right.
$$


Where $[X]$ is the sensitive matrix and :

$$
\begin{aligned}
& \beta_{l}=\frac{Q b^{2}}{R^{2} \sqrt{\pi} \sqrt{\lambda_{3}\left(\rho c_{p}\right)_{3}}} \\
& \beta_{2}=R c Q
\end{aligned}
$$

The optimal estimation is then :

$$
\hat{\beta}=\left([X]^{T}[X]\right)^{-1}[X]^{T} \hat{T} \text { with } \hat{\beta}=\left[\beta_{1}, \beta_{2}\right]^{T}
$$

The estimation parameters vector can be written $: \hat{\beta}=\beta+e_{\beta}$, where $\beta$ is the real parametres vector and $e_{\beta}$ is « the estimation parameters error »

Then $e_{\beta}$ is linked to $e_{T}$ by the relationship :

$$
\operatorname{cov}\left[e_{\beta}\right]=\left([X]^{T}[X]\right)^{-1} \sigma^{2}
$$

with $X$ sensitivities matrix and $\sigma$ stantard deviation on noise measurement :

$$
\operatorname{cov}\left[e_{T}\right]=\sigma^{2}[I]
$$

With linear expression (16), we obtain the covariance matrix (figure 4) :

$$
\operatorname{cov}\left[\begin{array}{l}
e_{\beta_{l}} \\
e_{\beta_{2}}
\end{array}\right]=\left[\begin{array}{ll}
2.6510^{-5} & -10^{-3} \\
-10^{-3} & 4.0210^{-2}
\end{array}\right]
$$

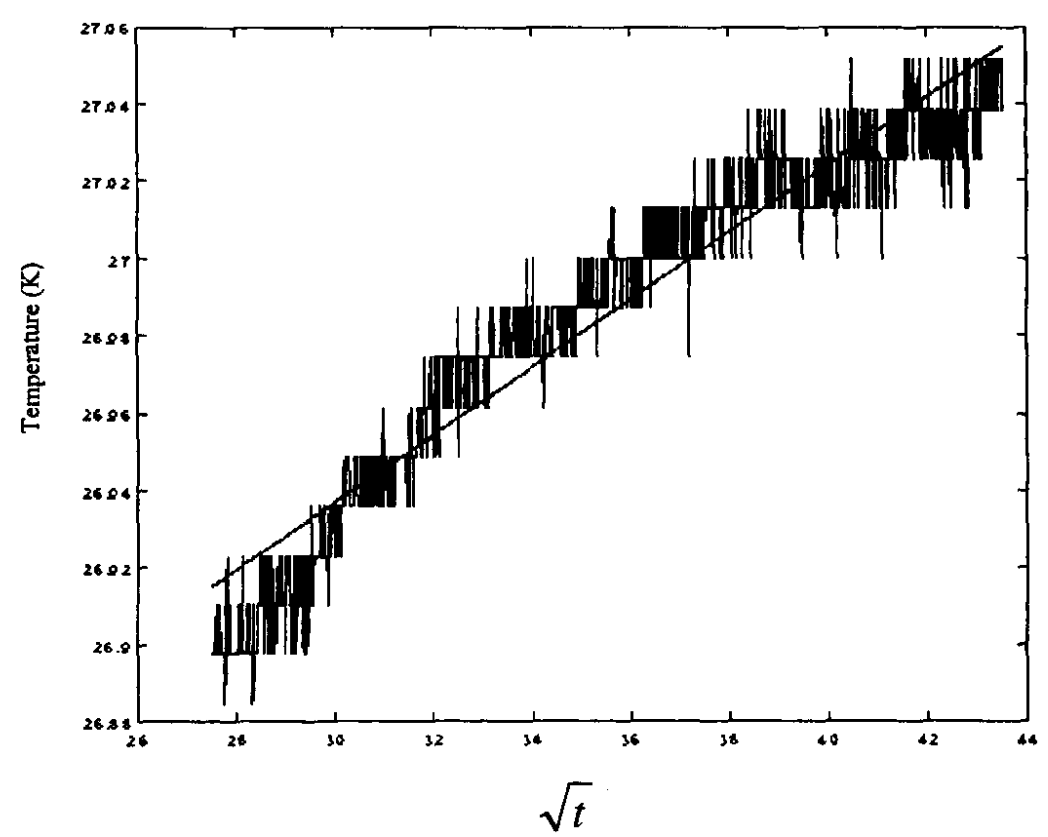

FIG 4

Result of the asymptotic assumption (16). 
These values indicate a very good occuracy. So we can estimate parameters but we can also know the estimation error on these parameters. Therefore slight systematic errors can occur with the determination of the other remaining thermophysical properties such as $\lambda_{2}, \rho c_{2}$, etc $\ldots$

\section{Remarks:}

* Limitations relative to thermal contact resistances :

One of the main assumptions here is to neglect the thermal contact resistances between layers 1 , 2 and 3. This induces a limitation with the samples to be measured. One criterion can be established:

$$
\frac{e_{2}}{\lambda_{2}}>10^{-4} W^{-1} m^{2} K
$$

* Choice of the sizes

We plot on figure 5, the evolution $T_{\text {conn }} / T$ where $T_{\text {conv }}$ is the temperature evolution at $r=0$ and $z=e$ in the case of convective losses on the lateral face of the sample is considered.

$b^{*}=b / R, e_{2}{ }^{*}=e_{2} / R$ and biot number $B i=h * R / \lambda=16.7$

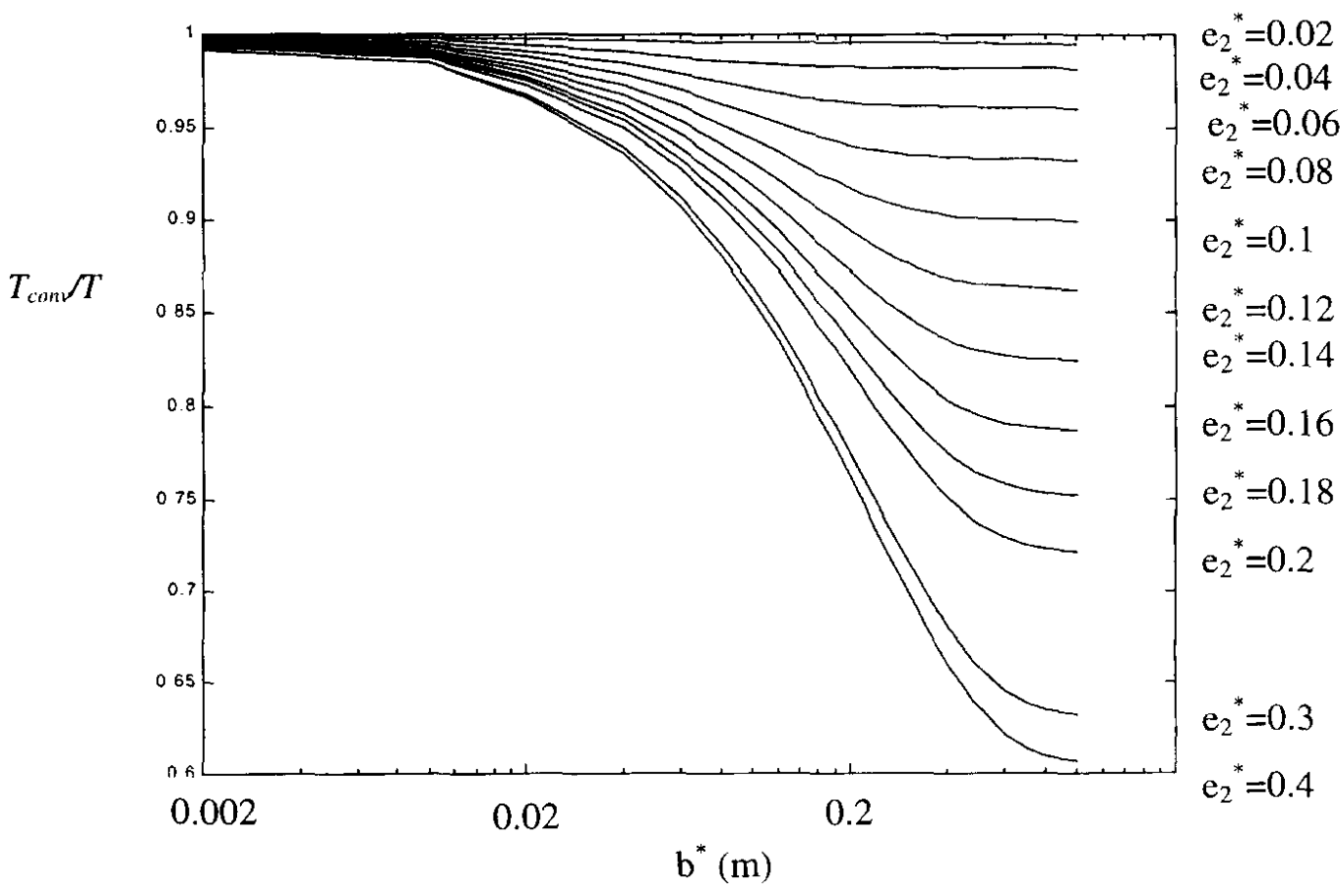

FIG 5

$T_{\text {cond }} / T$ fonction of $b$ and $e_{2}$ 
In order to fit with the previous assumption (adiabacity on lateral faces), it is important that the dimensions of the system be $R>b$ and $\mathrm{b} \approx \mathrm{e}_{2}$. In practise, we take $b=e 2=R / 10$.

\section{Conclusion}

The new device proposed here is complementary of the classical hot wire method. Our method remains simple, but we can control the heat flux diffusion in the sample.

We have shown that the calculation of the constriction resistance in the studied material quickly gives an exellent first estimation of the thermal conductivity. We can estimate the thermal conductivity and the volumic heat capacity with a classical numerical estimation which minimizes the norm beetween experimental result and complete model. We can also estimate the error on the parameters.

\section{Nomenclature}

$\begin{array}{ll}A, B, C, D & \text { Quadripole elements } \\ Q & \text { Excitation heat flux } \\ R c & \text { Contact thermal resistance } \\ T & \text { Temperature } \\ a & \text { Thermal diffusivity } \\ r, z & \text { Spatial coordinate } \\ p & \text { Laplace parameter } \\ t & \text { Time } \\ E & \text { Thermal effusivity } \\ b, R & \text { Lateral dimensions } \\ e & \text { Thickness } \\ \lambda & \text { Thermal conductivity } \\ \psi & \text { Laplace-Hankel flux } \\ \theta & \text { Laplace-Hankel temperature } \\ \rho c_{p} & \text { Volumetric thermal capacity } \\ \alpha & \text { Hankel parameter } \\ i & \text { indice relative to i-layer }\end{array}$

\section{References}

1 MUMAW J.R.,Heat Transmission Measurements in thermal insulations, ASTM STP 544, American Society for Testing and Materials, pp 193-211, 1973. 
2 CARSLAW H.S. and JAEGER J.C., Conduction of heat in solids, $2^{\text {nd }}$ edition, Oxford University Press, 1959.

3 PARKER WJ, JENKINS W, ABOTTJ., Flash method of determining thermal diffusivity, Heat capacity and thermal conductivity, J.Appl. Phys., vol 32, No 9, Sept, pp1679-1684, 1961.

4 DEGIOVANNI A., Diffusivité et méthode flash, Rev Gen de Therm., No 185, pp 417-442, 1977.

5 B.MARTIN, J.F DURASTANTI, B.PEUREUX, Méthode d'identification de la conductivité thermique des matériaux isolants, Entropie. Vol 147, pp 47-52, 1994.

6 X.ZHANG, Métrologie thermique par méthode quasi stationnaire: modélisation, identification, et application à la caractérisation de solides, Thése de doctorat INPL, 1993.

7 A.DEGIOVANNI, J.C BATSALE, A propos des conditions aux limites de 4éme et 5éme espèce, Int.J.Heat Mass Transfert. Technical note, Vol 5, pp 877-881, 1994.

8 T.PHAN, S.DILHAIRE, V.QUINTARD, D.LEWIS, W.CLAEYS, J.C BATSALE, Modeling and measurement of micrometric interconnect's transient temperature. Application to thermal conductivity identification, International Workshop on thermal investigations of integrated circuits and microstructures, 25-27 sept. 1996, Budapest.

9 J.C BATSALE, D.MAILLET, A.DEGIOVANNI, Extension de la méthode des quadripôles thermiques à l'aide de transformations intégrales: calcul de transfert transfert thermique au travers d'un défaut plan bidimensionnel, Int.J.Heat Mass Transfert. Vol 37, pp 111-127, 1994.

10 PH.LETURCQ, J.M.DORKEL, F.E.RATOLOJANAHARY, S.TOUNSI, A two-port network formalism for 3D heat conduction analysis in multilayered media, Int.J.Heat Mass Transfert. Vol 36,No 9, pp 2317-2326, 1993.

11 J.F BECK, K.J ARNOLD, Parameters estimation in engineering science, John Wiley \& Sons, New York, 1977.

12 J.F BECK, Sequential estimation of thermal parameters, Journal of Heat Transfer, Vol 99, pp $314,1977$.

13 H.STEHFEST, Remarks on algorithm 368. Numerical inversion of Laplace transform, A.C.M, Vol 53, No 10, pp 624, 1970.

14 Wh.PRESS, Sa.TEUKOLSKY, Wt.VETTERLING, Bp.FLANNERY, Numerical recipes, Cambridge university press, 1986

15 MINCO FRANCE, Z.I 09310 Aston France 